\title{
Research on the development of new energy industry based on A company
}

\author{
Yihang Lv ${ }^{1}$, Jingjing Kong ${ }^{1}$ \\ ${ }^{1}$ Chengdu Neusoft University, Chengdu, China
}

\begin{abstract}
China's energy development in the new era not only provides strong support for China's sustained and healthy economic and social development, but also makes positive contributions to maintaining world energy security, coping with global climate change and promoting world economic growth. Taking domestic hydrogen listed company a as an example, this paper analyzes the theory and data from the aspects of business model, core competitiveness and financial report in 2020, and finds that even with strong competitiveness, the business performance of company a, which has no major problems in business model, has suffered losses. In the future, the company or the development industry should be improved from both internal and external aspects. At the internal level, actively and steadily improve the management quality, increase R \& D efforts, optimize the project delivery process, and implement the financial intelligent transformation. At the external level, we are actively developing the market and expanding business. At the same time, we should strengthen publicity to the society and the public to guide consumers to trust and choose new energy products. The purpose of this paper is to provide some help for promoting the development of new energy industry in China.
\end{abstract}

\section{Background}

In December 2020, the Information Office of the State Council of the people's Republic of China issued the white paper "China's energy development in the new era", which pointed out that China's energy has entered a new stage of high-quality development, and put forward: "the prosperity of ecology means the prosperity of civilization. In the face of climate change, environmental risk challenges, energy and resource constraints and other increasingly serious global problems, China has established the concept of a community of shared future for mankind, promoted the comprehensive green transformation of economic and social development, actively participated in global energy governance while striving to promote clean and low-carbon development of its own energy, and worked with other countries to seek a new way to accelerate the sustainable development of global energy. President Xi Jinping announced at the general debate of the seventy-fifth UN General Assembly that China will enhance the state's independent contribution and adopt more effective policies and measures ${ }^{[1]}$ Carbon dioxide emissions will strive to peak before 2030, and strive to achieve carbon neutralization by 2060. China's energy development in the new era not only provides strong support for China's sustained and healthy economic and social development, but also makes positive contributions to maintaining world energy security, coping with global climate change and promoting world economic growth 《 "Made in China 2025" proposes to achieve the strategic goal of manufacturing power through "three steps". Under the background of the accelerated process of manufacturing upgrading and localization substitution, high-end equipment has become an important driving force for the transformation and upgrading of traditional industries, and the market demand for high-end equipment is growing rapidly. Based on a typical listed company a in China as an example, this paper analyzes the operation of the company in 2020, aiming to find the development path of domestic new energy industry companies through the study of case companies.

\section{Company overview}

The company started with clean energy equipment manufacturing, and is committed to becoming the "global technology leader in clean energy equipment overall solution provider". The company's business covers equipment manufacturing, engineering design, gas operation, Internet of things and technical services. The company's products have covered a number of provincial regions in China, as well as Europe, Africa, Southeast Asia, Central Asia, America and other regions. The application scenarios include LNG unattended vehicle filling equipment in London, UK, ultra-low temperature screen $\mathrm{CNG}$ dispenser in Russia, LNG Dewar filling equipment in Singapore, Sinopec West Shanghai and Anzhi oil and hydrogen integrated energy station, Beijing Daxing hydrogen science and Technology Park hydrogenation station, etc Zhangjiakou Weisan road hydrogenation station, Dongjiang Lake

author: 4761420@qq.com 
pure LNG passenger ship and other successful cases; the company mainly cooperates with PetroChina, Sinopec, CNOOC, major gas groups, local transportation groups, logistics, ports and wharfs, etc.

The core products of the company include hydrogenating machine, hydrogenating gun, calibrating device of compressed hydrogen filling machine, LNG fuel powered ship gas supply system, etc.

\section{Research on business status}

\subsection{Analysis of production and marketing mode}

The production workshop of the company strictly follows the $5 \mathrm{~S}$ management requirements and manages the site. The production of the company adopts the mode of "determining production by sales". According to the production plan issued by the material control, the company formulates quarterly and monthly production tasks, and constantly optimizes the formulation of product manufacturing process. At the same time, due to the uncertainty of customer demand, the production department implements modular and standardized production of standard products in advance, and determines the production plan according to the inventory. If the increase of customer demand is large, the production department will arrange the production according to the urgent production mode. The marketing center of the company has domestic / international business department, which is responsible for domestic and international business respectively; The company has established a relatively perfect marketing network and after-sales service system. The sales personnel are mainly responsible for maintaining the daily customer relationship in the area under their jurisdiction, maintaining communication and coordination with customers, understanding customer demand information, actively grasping market information and developing new customers.

\subsection{Analysis of company competitiveness}

\subsubsection{Advantages of hydrogen industry chain integration}

Since 2013, the company has been actively developing business in hydrogen related fields, and is the first domestic solution supplier of box type hydrogenation station. The company has been actively and continuously increasing its investment in the field of hydrogen energy. A number of key components of hydrogen energy filling equipment independently developed by the company have broken the international monopoly for the first time. The 70MPa hydrogenation gun and mass flowmeter of hydrogenation machine independently developed by the company are now in the field trial stage. In the field of hydrogenation station, the company has formed a comprehensive capacity covering the whole industrial chain from design to $\mathrm{R} \& \mathrm{D}$ and production of key components, complete equipment integration, installation and commissioning of hydrogenation station and technical service support.

\subsubsection{Technical advantages of cloud big data}

In recent years, the company has continuously strengthened the investment and research and development of Internet information technology, and successively launched hopnet Internet of things platform in the field of clean energy by using application information technology, cloud computing technology, big data technology, Internet of things technology and 4G / 5G communication technology. The platform breaks the docking bottleneck between different equipment manufacturers, equipment with different protocols, and different display platforms. It is the first unified safety supervision and operation platform to realize the functions of intelligent supervision of filling station equipment, intelligent operation management of filling station, and dynamic management of after-sales service in the clean energy filling industry.

\subsection{3 business integration advantages of Internet of things}

Over the years, the company has continuously increased the in-depth integration of manufacturing industry and cloud technology, and continuously deepened the business model of online and offline integration through the management of Internet of things. At present, the company has fully possessed the capabilities of project design, equipment manufacturing, construction management, installation and debugging, project operation and after-sales service in the field of clean energy utilization Information management, etc. Through the cooperative operation of several subsidiaries, the company ensures that the products and services provided by the company can meet the needs of customers at different stages and under different conditions in an integrated way, realizes the seamless connection of all links, forms a commercial operation mode with strong market competitiveness and high customer added value, and makes the company become an overall solution supplier of clean energy equipment, and has the ability to operate complex comprehensive clean energy projects.

\subsection{Data analysis based on 2020 Report}

The novel coronavirus pneumonia has spread rapidly since early 2020, and the world economy has been significantly affected, which has also had a great impact on the customers in the domestic and international markets of the company and the company. The novel coronavirus pneumonia has not been effectively controlled abroad until the date of this report, while domestic epidemic also has occasional and partial regional rebound, which has a great adverse effect on the company's operation in 2020.

In 2020, the company achieved operating income of 478.3712 million yuan, down $11.87 \%$ year on year; The 
net profit attributable to the shareholders of the listed company was RMB 1677350 , down $905.35 \%$ year on year; Net cash flow from operating activities was RMB 31.6376 million, down $116.67 \%$ year on year; The weighted average return on net assets was $-14.76 \%$, down $16.48 \%$ compared with the same period last year. The trend of operating income in recent years is shown in Figure 1.

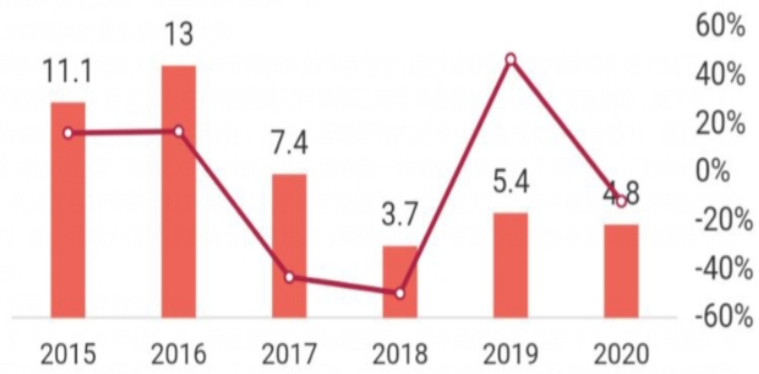

Fig. 1. revenue change chart

According to the company's 2020 report, in order to respond positively to the adverse effects brought by COVID-19, the company adopted measures such as increasing customer development efforts and adjusting marketing policies, resulting in an increase in sales expenses during the reporting period. In 2020, compared with that in 2019, the sales expenses increased by $31.57 \%$, the management expenses increased by $10.5 \%$, the R \& D expenses increased by $16.51 \%$, and only the financial expenses decreased by $26.45 \%$. The specific comparison is shown in Table 1.

Table 1. Data comparison between 2020 and 20219.

\begin{tabular}{|c|c|c|c|}
\hline & 2020 & 2019 & $\begin{array}{c}\text { increase and } \\
\text { decrease }\end{array}$ \\
\hline $\begin{array}{c}\text { Selling } \\
\text { expenses }\end{array}$ & $91,677,987$ & $669,678,347$ & $31.57 \%$ \\
\hline $\begin{array}{c}\text { Management } \\
\text { expenses }\end{array}$ & $78,422,824$ & $70,968,670$ & $10.50 \%$ \\
\hline $\begin{array}{c}\text { Financial } \\
\text { expenses }\end{array}$ & $9,494,128$ & $12,908,041$ & $-26.45 \%$ \\
\hline $\begin{array}{c}\text { R \& D } \\
\text { expenses }\end{array}$ & $32,052,062$ & $27,509,259$ & $16.51 \%$ \\
\hline
\end{tabular}

\section{4 problems and optimization suggestions}

It can be seen from the case company that even the hydrogen energy company, which is in the forefront of the domestic industry, has strong competitiveness and business ability, can not make the company profit at present, and the latest 2020 report is also in a state of loss. For the future development of the company, it is suggested to start from the internal and external aspects.

\subsection{1 external level}

Actively develop the market, expand business, based on the domestic, deeply cultivate the main business of LNG vehicle refueling equipment, actively expand the hydrogen and marine refueling market, and increase the research and development and sales of key parts. At the same time, we should actively apply to the state for various policy support and financial subsidies to make the state and society realize that the development of new energy is the trend of the times, and at the same time, we should convey to the society and the public that hydrogen energy is a very clean energy. Let people realize the benefits of hydrogen energy, when using new energy, give priority to the use of this new energy. In addition, we can timely consider actively integrating industrial resources by means of investment in new construction, acquisition, merger and acquisition, so as to make it bigger and stronger.

\subsection{2 internal level}

First, we should actively and steadily improve the quality of management. We should continue to strengthen the quality work, adhere to the principle of quality priority, constantly revise and improve the quality management system, carry out various quality activities, implement the main responsibility of safety, strictly abide by the safety bottom line, strengthen the quality awareness, and improve the quality level. Second, increase $\mathrm{R} \& \mathrm{D}$ efforts. Combined with the latest $5 \mathrm{~g}$ technology and Internet of things technology, we develop various products and software platforms. Third, optimize the project delivery link. The project management system is used to realize the real-time information management and monitoring of the whole process from contract signing to delivery. Fourth, financial management intelligent transformation. The electronic reimbursement system is introduced to realize the online, digital and electronic invoice of the company's sales, expenses, supply chain and other businesses, so as to improve the employees' satisfaction with reimbursement, improve the employees' satisfaction with reimbursement, open up the reimbursement business process, and improve the audit quality and efficiency.

\section{Conclusion}

China's energy development in the new era not only provides strong support for China's sustained and healthy economic and social development, but also makes positive contributions to maintaining world energy security, coping with global climate change and promoting world economic growth. Taking domestic hydrogen listed company a as an example, this paper makes theoretical and data analysis from the aspects of business model, core competitiveness and financial report in 2020, and finds that even a company with strong competitiveness and no big problems in business model has made losses in its business performance. In 
the future, the company or the development industry should be improved from both internal and external aspects. At the internal level, actively and steadily improve the management quality, increase R \& D efforts, optimize the project delivery process, and implement the financial intelligent transformation. At the external level, we are actively developing the market and expanding business. At the same time, we should strengthen publicity to the society and the public to guide consumers to trust and choose new energy products. Through the research of this paper, it aims to provide reference direction for the development of domestic new energy enterprises, and make a certain contribution to promote the development of China's new energy industry.

\section{Acknowledgements}

This research was supported by teaching reform project of Chengdu Neusoft University in 2021.

\section{References}

1. Wei Tang, Peng Wu, Yu Zhang, Xiaodong Cao. "Analysis on the Current Situation and Development Trend of China's Electrification Level and Electric Energy Substitution under the Background of Carbon Neutral", IOP Conference Series: Earth and Environmental Science, 2021

2. Shen Huayu,Hou Fei. Trade policy uncertainty and corporate innovation evidence from Chinese listed firms in new energy vehicle industry[J]. Energy Economics,2021,97.

3. Wang Yuru, Li Yuanyuan, Guo Jiayuan. Research on the impact of government subsidies on the development of new energy industry [J]. Investment and cooperation, 2021 (03): 191-192

4. Lu Ye,Liu Qin,Li Jia Hui. The impact of government subsidies on the green innovation capability of new energy automobile companies[J]. IOP Conference Series: Earth and Environmental Science,2021,680(1).

5. Fan Xin. Gains and losses of new energy industry policy from the perspective of millet car making [n]. China business daily, 2021-04-05 (A07).

6. Wang Yuru, Li Yuanyuan, Guo Jiayuan. Research on the impact of government subsidies on the development of new energy industry [J]. Investment and cooperation, 2021 (03): 191-192.

7. Yang Tong,Xing Chen,Li Xinyu. Evaluation and analysis of new-energy vehicle industry policies in the context of technical innovation in China[J]. Journal of Cleaner Production,2021,281.

8. Liu Wen he novel coronavirus pneumonia epidemic impact on the global energy industry chain "four stage" model analysis and coping with [J]. industrial technology economy, 2021,40 (01): 3-12. 